\title{
Financial Shocks and Credit Cycles ${ }^{1}$
}

\author{
Mikhail Mamonov, \\ Institute for International Studies, MGIMO University; CERGE-EI \\ mikhail.mamonov@cerge-ei.cz \\ Vera Pankova, \\ Centre for Macroeconomic Analysis and Short-term Forecasting (CMASF) \\ vpankova@forecast.ru \\ Renat Akhmetov, \\ Centre for Macroeconomic Analysis and Short-term Forecasting (CMASF) \\ rakhmetov@forecast.ru \\ Anna Pestova, \\ Institute for International Studies, MGIMO University; CERGE-EI \\ anna.pestova@cerge-ei.cz
}

This paper compares the contribution of internal and external financial shocks to the formation of credit cycle phases using crosscountry quarterly data for 27 countries, including advanced and emerging economies, for the period from 1990 through 2019. To conduct comparative analysis, we apply IV Probit models of the credit cycle which take into account the relationship between the credit and business cycles the inertia of the cycles and the non-linearity of the transmission of internal and external financial shocks to the economy through the credit market. In our sample of countries, the transmission of shocks to credit cycle phases proves to be non-linear (a switching effect is observed depending on the time elapsed since the shocks occurred); with the economic effect of the external capital inflow shock being in absolute value twice as strong as that of the bank credit supply shock (on average for the current and subsequent quarters); in turn, the bank credit supply shock is twice as strong as the monetary policy shock. A counterfactual analysis of the role of financial shocks in the formation of the credit cycle in Russia indicates an increase in the effectiveness of the monetary authorities in terms of their ability to control the phases of the credit cycle and, accordingly, a relative decrease in the role of credit supply shocks, while the global financial cycle retains its dominance.

Keywords: credit supply shocks, monetary policy shocks, global financial cycle, business cycle, recessions

JEL Codes: E32, E52, E58, F32, F44
Citation: Mamonov, M., Pankova, V., Akhmetov, R. and Pestova, A. (2020). Financial Shocks and Credit Cycles. Russian Journal of Money and Finance, 79(4), pp. 45-74.

doi: $10.31477 /$ rjmf.202004.45

\footnotetext{
${ }^{1}$ The authors would like to thank the CMASF experts Ilya Medvedev, Artem Deshko, and Aleksey Rybalka for their help in setting up the databases. The study was funded by the Russian Foundation for Basic Research under Research Project No. 18-310-20015.
} 


\section{Introduction}

After the global financial crisis of 2007-2009, researchers increasingly agree that financial shocks not only transmit real shocks to the economy but can also act on their own as full-fledged triggers for recessions and the economic cycle phases (Gertler and Kiyotaki, 2010; He and Krishnamurthy, 2012; Jermann and Quadrini, 2012; Brunnermeier and Sannikov, 2014; Perri and Quadrini, 2018; Gertler et al., 2020). The authors of previous studies also conclude that recessions last longer, and the economic downturn is deeper if recessions are accompanied by financial crises (Reinhart and Rogoff, 2009; Claessens et al., 2012). Accordingly, it is important to find out how financial shocks - internal (monetary and credit shocks) and external (capital inflow shocks) - affect the changes in credit cycle phases in different countries, and how the economic effects of these shocks are linked. This paper aims to answer these questions.

We compared the contribution of internal and external financial shocks to the formation of credit cycle phases using cross-country quarterly data for 27 countries, including advanced and emerging economies, for the period from 1990 through 2019. To identify internal financial shocks, we applied restrictions on the signs of impulse response functions in structural vector autoregressions (SVAR), following the approach proposed by Gambetti and Musso (2017); to identify external financial shocks, we used a variable of the global financial cycle (GFC) from MirandaAgrippino and Rey (2020). Next, applying the BBQ algorithm (Bry-Boschan Quarterly algorithm) from Harding and Pagan (2002), we constructed the business and credit cycle binary variables. Finally, we estimated IV Probit (Instrumental Variable Probit) models of the credit cycle that take into account the relationship between the credit and the business cycle, the inertia of the cycles and, in essence, the internal and external financial shocks and their non-linear transmission to the economy through the credit market.

Our calculations showed that the transmission of internal and external financial shocks to the phases of the credit cycle might be non-linear in the considered sample of countries (the underlying effects switch signs depending on the time elapsed since the shocks occurred); of these shocks, the external capital inflow (GCI) shock, in the current and subsequent quarters, was on average approximately twice as strong as the economic effect of the credit supply (CS) shock. The CS shock, in turn, might be twice as strong as the monetary policy (MP) shock. However, we found significant heterogeneity across countries. Thus, a counterfactual analysis for the Russian economy indicates that, though the economic effect from monetary shocks might have exceeded that of the credit supply shocks, - which can witness a raise in the effectiveness of the Russian monetary authorities in terms of their ability to control credit cycle phases during the local economic crisis of 2014-2015 nevertheless, the dominating shocks were still the external ones.

The results of this paper may have practical implications for central banks. The analysis of the interrelation of various financial shocks in determining the 
current phase of an economic cycle contributes to the existing literature on credit cycles (Aikman et al., 2015) and on forecasting financial crises (Schularick and Taylor, 2012; Greenwood et al., 2020) and recessions (Kauppi and Saikkonen, 2008; Nyberg, 2010; Antunes et al., 2018).

The paper has the following structure. Section 2 describes the methodology of SVAR models in the context of identification of financial shocks and that of the IV Probit models for comparative estimation of the impact of financial shocks on credit cycle phases. Section 3 presents cross-country data and describes key trends in macro-financial data for various sub-samples of countries. Section 4 contains key findings, a counterfactual analysis of credit cycles in the Russian economy and robustness checks of the key results. Section 5 presents the conclusion of the paper.

\section{Empirical design}

\subsection{Identifying financial shocks: the SVAR approach}

To identify aggregate financial shocks for each country separately, we used vector autoregression (VAR) models with restrictions on the signs of impulse response functions of endogenous variables. The identification scheme of sign restrictions follows Gambetti and Musso (2017), in which the authors identified four types of shocks in a system of five endogenous variables: credit supply (CS), monetary policy (MP), aggregate demand (AD), and aggregate supply (AS) shocks. The five endogenous variables considered by the authors include real GDP index, consumer price index (CPI), the monetary policy interest rate (short-term interest rate), lending rate and loan volumes. The sign restrictions on these variables for each of the four shocks were set by the authors in accordance with theoretical work describing the derivation of the necessary first-order conditions to determine the general equilibrium in the economy. The scheme of the sign restrictions is presented below (Table 1).

Table 1. Scheme of sign restrictions in the SVAR model for identification of financial shocks

\begin{tabular}{l|l|l|l|l|l} 
& GDP & Inflation & $\begin{array}{l}\text { Short term } \\
\text { interest rate }\end{array}$ & Lending rate & Loan volumes \\
\hline Credit supply shock (CS) & + & + & + & - & + \\
\hline Monetary policy shock (MP) & - & - & + & $\mathrm{n} / \mathrm{r}$ & $\mathrm{n} / \mathrm{r}$ \\
\hline Aggregate demand shock (AD) & + & + & + & + & $\mathrm{n} / \mathrm{r}$ \\
\hline Aggregate supply shock (AS) & + & - & $\mathrm{n} / \mathrm{r}$ & $\mathrm{n} / \mathrm{r}$ \\
\hline
\end{tabular}

Note: '+' ('-') - the value of the variable indicated in the column must increase (decrease) in response to the shock indicated in the row. ' $\mathrm{n} / \mathrm{r}$ ' - no restriction on the variable.

Source: Gambetti and Musso (2017)

In accordance with the shock identification scheme given in Table 1, when evaluating the SVAR model, we assumed that a positive CS shock corresponds to a simultaneous increase in the loans from the banking sector and a decrease in the 
lending rate, as well as an acceleration of economic dynamics entailing price growth and a response from the central bank aimed at curtailing it (an increase in short-term interest rate). Then, along with the CS shock, we set a restrictive (unlike in Gambetti and Musso, 2017) MP shock defined as an increase in the short-term interest rate accompanied by lower inflation and demand for money (M2). Finally, together with the CS and MP shocks, we set aggregate demand (AD) and aggregate supply (AS) shocks. In the case of a positive $\mathrm{AD}$ shock, the economy faces a simultaneous rise in the overall levels of prices and output, causing the central bank to try to cool the economy down by raising the short-term interest rate, which in turn puts upward pressure on all other interest rates in the economy, including the lending rate. In such a situation, economic agent credit indebtedness can grow if the positive effect of income growth exceeds the negative effect of the increased lending rates, and vice versa. Since the result of the two effects is not a priori obvious, the loan variable in this scheme is not restricted. The identification of a positive AS shock according to Gambetti and Musso (2017) is very minimalistic: it is only assumed that the opposite reactions of prices and output - that is, a reduction in inflation and economic growth. This is due to the fact that AS shocks (e.g., positive technology innovations) are not associated with inflationary effects, and therefore, as a rule, do not lead to a restrictive response from the central bank. Similar schemes for identifying financial shocks, in particular, credit shocks, are used in Eickmeier and $\mathrm{Ng}$ (2015).

The technical implementation of these ideas is shown below. First, a standard VAR model is specified for time series of $N$ endogenous variables and $P$ lags (Sims, 1980; Kilian and Lütkepohl, 2017):

$$
y_{t}=A_{1} y_{t-1}+\cdots+A_{p} y_{t-p}+u_{t}
$$

where $y_{t}$ is the $N \times 1$ vector of endogenous variables $(N=5$ in our case); $A_{h}(h=1 \ldots P)$ is the $N \times N$ matrix of unknown coefficients to be estimated; $u_{t}$ are the regression errors (in reduced form) with zero means $E\left(u_{t}\right)=0$ and covariance matrix $E\left(u_{t} u_{t}^{\prime}\right)=\Sigma_{u}$.

As we know, the time series of the estimated regression errors in the vector $u_{t}$ can be correlated with each other and, accordingly, cannot be interpreted as structural variable shocks. To identify shocks, these regression errors are usually orthogonalised by using certain linear combinations of these errors, and it is in such linear combinations that the signs of the coefficients must comply with the abovedescribed scheme of restrictions on the signs of impulse response functions: ${ }^{2}$

$$
\varepsilon_{t}=Q u_{t}
$$

where $Q$ is the $N \times N$ matrix of unknown coefficients (the 'rotation matrix') for linear combinations of the original regression errors that ensure the orthogonality of these combinations through the imposition of sign restrictions in the estimation;

\footnotetext{
2 The method of orthogonalisation with restrictions on the signs of impulse response functions was proposed in Uhlig (2005), which analysed the transmission of monetary shocks in the US economy.
} 
$\varepsilon_{t}$ are the orthogonalised shocks. The procedure for searching for orthogonal combinations is well-known and described, for example, in Kilian and Lütkepohl (2017). We only note that in the system of five variables, four shocks correspond to the shocks described above: credit supply (CS), monetary policy (MP), aggregate demand (AD), and aggregate supply (AS) shocks, and the fifth shock (i.e., the fifth linear combination) encompasses all other innovations not accounted for by the model, but observed in the five variables of the model (Gambetti and Musso, 2017).

Although quarterly data were used for estimation of (1) and (2) for each country, the sample size - 70 to 170 observations depending on the country (see Section 3) - is fairly small relative to the number of estimated coefficients $(5 \times(5 \times 4+1)=5 \times 21=105$ coefficients in total in five equations). This leads to the well-known problem of the 'curse of dimensionality', which can be solved by applying a Bayesian estimation approach. ${ }^{3}$ To implement these methods, we wrote a Matlab code enabling us to obtain estimates of VAR models with restrictions on the signs of impulse response functions for each country. ${ }^{4}$ To calculate the estimates, we used so-called Minnesota prior distributions for the coefficients in the model $(1)^{5}$ and flat priors for the coefficients of linear combinations (2). For the specification of the Minnesota prior distribution, we applied standard values of the prior distribution hyperparameters used in the literature: $\lambda_{1}=0.2$ (general degree of compression the space of the estimated coefficients), $\lambda_{2}=0.5$ (degree of compression of the effect of other variables' lags on each of the five variables in model (1)), and $\lambda_{3}=2$ (degree of compression of the effect of deeper lags of each variable). To obtain an empirical posterior distribution of the coefficient estimates in (1) and (2), we carried out 5,000 extractions from the corresponding prior distribution, with the first 2,500 extractions excluded from further analysis (burn-in). ${ }^{6}$

As a result, we obtained 2,500 time series estimates for each of the four shocks (CS, MP, AD, AS) for each country in the sample. These 2,500 estimates form the posterior distribution of each shock, and for further analysis of the impact of these shocks on the credit cycles, we extract the median values of the shocks:

$$
\hat{\varepsilon}_{t}^{(j)}, \quad j=\langle C S, M P, A D, A S\rangle .
$$

\subsection{Financial shocks and credit crises: an instrumental approach}

This work focuses on a comparative analysis of the role of internal and external financial shocks - monetary policy (MP), credit supply (CS) shocks, and the external

\footnotetext{
${ }^{3}$ For example, see the review in Pestova and Mamonov (2016a).

${ }^{4}$ The Matlab code is posted on the authors' website. See https://sites.google.com/view/ mikhailmamonov/policy-analysis

${ }^{5}$ Similar distributions were used earlier to build a BVAR model of the Russian economy in Deryugina and Ponomarenko (2015), Pestova and Mamonov (2016b), and Demeshev and Malakhovskaya (2016).

${ }^{6}$ Such 'burn-in' of the initial estimates of the iterative algorithm is usually carried out to reduce the negative effect of (possibly) biased initial values of the estimation matrices of coefficient estimates and estimates of their covariance matrices set as ordinary least squares (OLS) estimates.
} 
capital inflows shock within the global financial cycle (GFC) - in determining the phase of the credit cycle. We obtain MP and CS shocks from our SVAR analysis by country (see Section 2.1), and GFC is taken from Miranda-Agrippino and Rey (2020). ${ }^{7}$ Obviously, there are other factors besides these shocks that affect credit cycles, and to be confident in the results of the comparative analysis, we must take such factors into account while keeping the empirical model as compact and interpretable as possible. One way to achieve this goal is to incorporate the business cycle phase into the model for the credit cycle phase: the former absorbs many macroeconomic and financial factors that may be relevant for considering the latter. ${ }^{8}$ However, here we face the problem of endogeneity between the business and credit cycles.

To solve the endogeneity problem, we apply a two-step estimation method using IV Probit instrumental variables. In the first step of this method, we estimate model (4) of the probability of a recession, and in the second step we estimate model (5) of the probability of credit crisis with the estimated value of the probability of recession obtained in the first step as one of the predictors. ${ }^{9}$ The first and the second steps have different sets of explanatory variables: to model the business cycle, we use aggregate demand (AD) and aggregate supply (AS) shocks estimated together with MP and CS shocks in the SVAR model for each country (see Section 2.1). $\mathrm{AD}$ and AS shocks are determined as output shocks, and not credit shocks, so we assume that they affect the credit cycle not directly but only through the phase of the business cycle due to the changing income and expenditure balances of the economic agents. The three financial shocks that are the focus of our paper, MP, CS, and GFC shocks, are the common variables for the first and second steps. As for the GFC variable, what we are interested in is not the global financial cycle per se as a predictor of the change in the phases of business and credit cycles, but the part of the variation in a country's capital inflows ${ }^{10}$ explained exactly by the dynamics

\footnotetext{
${ }^{7}$ The GFC time series is publicly available on Helen Rey's website: http://www.helenerey.eu/ RP.aspx?pid=Published-Papers_en-GB\&aid=291587444_67186463733. GFC is the first principal component of approximately 800 variables representing the global prices of various financial assets. By construction, GFC is standardised and centred around zero. Positive GFC values correspond to the expansion phase of the global financial cycle, while negative values correspond to the contraction phase.

8 The relationship between business cycles and financial cycles is explored in a large number of empirical studies. For example, Reinhart and Rogoff (2009) show that the deeper the previous phases of the business cycle, the deeper the current phases of the financial cycle, in particular, historical data on banking crises in many advanced and emerging economies in the 20th century.

${ }^{9}$ The use of a two-step estimation method with instrumental variables is preferable in comparison to an independent two-step procedure (where the estimates of the first and second steps are obtained independently) since this approach takes into account the uncertainty associated with the fact that the probability of a recession obtained in the first step is an estimate, not an actual value.

${ }^{10}$ We used two alternative variables, the volume of gross capital inflow ('Other investments' in the standard components of the Balance of Payments) relative to GDP and the volume of net capital inflow (inflow of other investments into the country net of other investments abroad) relative to GDP. Although the final conclusions do not qualitatively change depending on the use of one or the other of these two variables, we use gross capital inflows for baseline results as we are more interested in the attractiveness of each country for international investors rather than the investment instruments of these countries abroad.
} 
of the global financial cycle (rather than by the dynamics of domestic fundamental factors determining the attractiveness of the country for international investors).

The general specification of the IV Probit model to be estimated is as follows:

$$
\begin{aligned}
& \operatorname{Pr}\left\{Y_{i t}^{B C}=1 \mid \alpha_{i}^{B C}, X_{i t-k}\right\} \\
& \quad=\Phi\left(\alpha_{i}^{B C}+\beta_{1} \hat{\varepsilon}_{i t-k}^{A D}+\beta_{2} \hat{\varepsilon}_{i t-k}^{A S}+\beta_{3} \hat{\varepsilon}_{i t-k}^{M P}+\beta_{4} \hat{\varepsilon}_{i t-k}^{C S}+\beta_{5} \widehat{G C} I_{i t-k}\right) \\
& \begin{array}{r}
\operatorname{Pr}\left\{Y_{i t}^{C C}=1 \mid \alpha_{i}^{C C}, X_{i t-k}, \widehat{Y_{l t}^{B C}}\right\} \\
\quad=\Phi\left(\alpha_{i}^{C C}+\gamma_{1} \hat{\varepsilon}_{i t-k}^{M P}+\gamma_{2} \hat{\varepsilon}_{i t-k}^{C S}+\gamma_{3} \widehat{G C} I_{i t-k}+\delta_{1} \widehat{Y_{i t}^{B C}}\right)
\end{array}
\end{aligned}
$$

where $i$ is the country, $t$ is the quarter, $\Phi()$ is the cumulative function of the standard normal distribution, and $Y_{i t}^{B C}$ is the binary variable reflecting the current stage of a business cycle: $Y_{i t}^{B C}=1$, country $i$ is in a recession in the quarter $t$, and if $Y_{i t}^{B C}=0$, it is in a stage of economic growth. $Y_{i t}^{C C}$ is the binary variable similarly reflecting the current stage of the credit cycle. Both binary variables are obtained by using the BBQ algorithm by Harding and Pagan (2002). ${ }^{11} \alpha_{i}^{j}$ is unobservable component (fixed effect) specific for country $i$, reflecting its peculiar vulnerability to recessions $(j=B C)$ and credit crises $(j=C C) . X_{i, t-k}$ is the set of explanatory variables for country $i$ in quarter $i-k$; $k$ is the lag order from 0 to 12 quarters. In the basic specification of the model, we set $k=0$ for the estimation of the interrelation of three types of financial shocks in determining the current phase of the credit cycle (see Section 4.2), and in additional specifications we consider the case of $k=1,2, \ldots, 12$ (see Section 4.3). Depending on the equation, the set of regressors $X$ includes the following shocks: $\hat{\varepsilon}_{i t-k}^{A D}$ - the aggregate demand (AD) shock, $\hat{\varepsilon}_{i t-k}^{A S}$ - the aggregate supply (AS) shock, $\hat{\varepsilon}_{i t-k}^{M P}$ - the monetary policy (MP) shock, $\hat{\varepsilon}_{i t-k}^{C S}$ - the credit supply (CS) shock and $G \widehat{C I}_{i t-k}$ - the capital inflow shock, which is the fitted value of the variable of the ratio of gross capital inflow ('Other investments' item in the Balance of Payments' standard component representation) into country $i$ to its GDP obtained from equation (6), with the global financial cycle indicator $G F C_{t}$ from Miranda-Agrippino and Rey (2020) as the key explanatory variable:

$$
G C I_{i t}=\alpha_{i}^{G C I}+\varphi G F C_{t}+u_{i t}^{G C I},
$$

where $\alpha_{i}^{G C I}$ is the fixed effect of country $i$, reflecting its average attractiveness for international investors over the entire time horizon under consideration, and $u_{i t}^{G C I}$ is the regression error in the equation (6).

\footnotetext{
11 The dates of credit and business cycles by country obtained using the BBQ algorithm are generally comparable to the dates of macroeconomic recessions and credit (banking, financial) crises published on the websites of international organisations (NBER, Economic Cycle Research Institute) and in empirical literature (Laeven and Valencia, 2020; Detken et al., 2014; Duprey et al., 2017). The comparison results are given in the Appendix (see Tables A1 and A2).
} 
Equations (4) and (5) are estimated using the maximum likelihood estimation method within the IV Probit procedure with HAC-robust ${ }^{12}$ standard errors, and equation (6) is estimated using a robust OLS method.

Since the variables of the three types of shocks included in equation (5) $-\hat{\varepsilon}_{i t-k \text {, }}^{M P}$, $\hat{\varepsilon}_{i t-k}^{C S}, \widehat{G C I}_{i t-k}$-are not standardised and can differ significantly in variance, and since the estimates of the coefficients in Probit models are usually not interpretable, estimating the relative role of these shocks in shaping or predicting a change in the credit cycle phase is problematic. To deal with this problem, we estimate the economic effects of each of the three shocks as follows: after estimating the Probit model, we calculate the marginal effects corresponding to the coefficients $\gamma_{1}, \gamma_{2}, \gamma_{3}$ - that is, $\partial \operatorname{Pr}\left(Y_{i t}^{C C}=1 \mid \ldots\right) / \partial \hat{\varepsilon}_{i t-k}^{M P}$, $\partial \operatorname{Pr}\left(Y_{i t}^{C C}=1 \mid \ldots\right) / \partial \hat{\varepsilon}_{i t-k}^{C S}$ and $\partial \operatorname{Pr}\left(Y_{i t}^{C C}=1 \mid \ldots\right) / \partial G \widehat{C I}_{i t-k}$, and multiply each of them by one intra-sample standard deviation of the corresponding indicators $\hat{\varepsilon}_{i t-k}^{M P}, \hat{\varepsilon}_{i t-k}^{C S}$, $\widehat{G C I}_{i t-k}$. In such a way, we obtain estimates for credit crisis probability in period $t$ in response to monetary policy, domestic credit supply and external financing shocks in period $t-k$ :

$$
\begin{gathered}
\Delta \widehat{P r}_{i t}^{M P}=\frac{\partial \operatorname{Pr}\left(Y_{i t}^{C C}=1 \mid \ldots\right)}{\partial \widehat{\varepsilon}_{i t-k}^{M P}} \cdot s d\left(\hat{\varepsilon}_{i t}^{M P}\right), \\
\Delta \widehat{P r}_{i t}^{C S}=\frac{\partial \operatorname{Pr}\left(Y_{i t}^{C C}=1 \mid \ldots\right)}{\partial \hat{\varepsilon}_{i t-k}^{C S}} \cdot s d\left(\hat{\varepsilon}_{i t}^{C S}\right), \\
\Delta \widehat{P r}_{i t}^{G C I}=\frac{\partial \operatorname{Pr}\left(Y_{i t}^{C C}=1 \mid \ldots\right)}{\partial \widehat{G C} I_{i t-k}} \cdot s d\left(\widehat{G C} I_{i t-k}\right) .
\end{gathered}
$$

The hypotheses of our study are as follows.

First, restraining monetary policy shocks reduce the probability of credit crises in the short run, $\Delta \widehat{P r}_{i t}^{M P}<0$ (Short-Run, SR), but increase it over longer horizons, $\Delta \widehat{P r}_{i t}^{M P}>0$ (Long-Run, $L R$ ). The former is due to the fact that an unexpected increase in the rate may quickly filter out less profitable projects in the economy (which would receive loan financing in the absence of the shock but as a result would not be able to settle their obligations in full). The latter is due to the fact that the remaining projects in the economy may find it more difficult to service debt in the long run due to higher rates (compared to zero-shock conditions).

Second, positive shocks of bank credit supply by the domestic financial system and positive external financing shocks also reduce the probability of a credit crisis over the short horizon, $\Delta \widehat{P r}_{i t}^{C S}<0(S R)$ and $\Delta \widehat{P r}_{i t}^{G C I}<0(S R)$, but increase it over longer horizons, $\Delta \widehat{P r}_{i t}^{C S}>0$ (LR) and $\Delta \widehat{P r}_{i t}^{G C I}>0$ (LR). In the first case, the decisive role is played by the effect of borrowers' ability to refinance

\footnotetext{
${ }^{12}$ HAC (Heteroskedasticity and Autocorrelation Consistent) provides estimates of standard errors adjusted for possible heteroskedasticity and autocorrelation in equation errors. In addition to HAC, we also re-estimated all equations using a bootstrap (replication $=1,000$, with repetitions) to account for the fact that our explanatory variables for both the second and the first steps are estimates, and not actual data. The transition to such a procedure does not produce qualitative changes in the baseline results.
} 
previous debts with new ones on the domestic or foreign market, delaying the onset of the credit crisis. In the second case, we see the effect of borrowers' inability to participate in the 'pyramid' of debt refinancing in the longer term. The latter is confirmed by studies on forecasting financial crises over long horizons depending on the dynamics of bank credit (Schularick and Taylor, 2012) and asset prices (Greenwood et al., 2020). ${ }^{13}$

The key question - the one on the ratio of the magnitudes of economic effects (7)-(9) remains open for empirical verification since it is not obvious in advance which of the three shocks may be the most substantial in terms of the phase of the credit cycle.

\section{Cross-country data}

To estimate cross-country SVAR models and subsequently estimate the impact of financial shocks on the phases of credit cycles, we have developed a Python code that allows us to collect comparable data series for various indicators by connecting to the APIs of the International Monetary Fund (IMF) International Financial Statistics and Balance of Payments databases (GDP, inflation, capital inflows), as well as the Bank for International Settlements (BIS) (statistics on bank loans) and OECD (interest rates) databases.

\subsection{Descriptive statistics of variables used}

The initial sample included data for 37 advanced and emerging economies from 1990Q1 through 2019Q1 (with missing values).

Table 2 presents descriptive statistics of five variables used for estimation of SVAR models similar to those used in Gambetti and Musso (2017), and Table 3 shows descriptive statistics of all variables (except SVAR estimates of shocks) for the IV Probit model of the credit cycle. To estimate the SVAR models, we had data available for 33 countries out of 37 in the initial sample, and to estimate the IV Probit model, data for 27 countries, taking into account the missing values. The number of countries included in the sample for estimating the IV Probit model depended on the availability of quarterly data on bank loans in the BIS database. It should be noted that such quarterly data are also available in other databases (IMF), but only the database of the BIS provides them for a wider time horizon. The final sample used for the regression analysis includes 27 advanced and emerging economies ${ }^{14}$ and about 2,000 observations in a 'country/quarter' format. To calculate the indicator variables of the business cycle (BC) and credit cycle ( $Y_{i t}^{B C}$ as well as $Y_{i t}^{C C}$ accordingly),

\footnotetext{
${ }^{13}$ For example, Greenwood et al. (2020) show that rapid growth in credit and asset prices raises the probability of a financial crisis by 40 p.p. over a three-year horizon based on post-WWII cross-country data.

${ }^{14}$ Austria, Australia, Belgium, Brazil, the United Kingdom, Hungary, Germany, Greece, Israel, Indonesia, Ireland, Spain, Italy, Canada, Colombia, Mexico, the Netherlands, New Zealand, Portugal, Russia, the USA, Thailand, France, the Czech Republic, Chile, South Africa, and Japan.
} 
we used the BBQ algorithm to identify turning points (peaks and troughs) in the dynamics of specified indicators (Harding and Pagan, 2002). In particular, to isolate the business cycle, we applied the BBQ algorithm to the quarterly data on the basic real GDP index, and to isolate the credit cycle, we applied it to the quarterly data on the real bank loans.

An analysis of descriptive statistics shows that in our sample of 27 countries the average frequency of credit crises is twice as high as the frequency of recessions ( $26 \%$ of observations versus $13 \%$ ) - that is, the periods of the credit crises took on average about 7.5 years out of the 29 years considered. We note the significant variation in the annual dynamics of banking sector loans, with an almost 100 p.p. spread (from $-54 \%$ in Indonesia during the Asian crisis of the late 1990s to more than $+40 \%$ in Malaysia in the early 1990 s as well as in Russia and Turkey on the verge of the global financial crisis of 2007-2009).

Table 2. Descriptive statistics for SVAR models

\begin{tabular}{|c|c|c|c|c|c|}
\hline & $\begin{array}{l}\text { Number } \\
\text { of observations }\end{array}$ & $\begin{array}{l}\text { Mean } \\
\text { value }\end{array}$ & $\begin{array}{l}\text { Standard } \\
\text { deviation }\end{array}$ & Min. & Max. \\
\hline Real GDP index (seasonally adjusted) & 2,848 & 91.96 & 20.97 & 35.19 & 176.20 \\
\hline $\begin{array}{l}\text { Consumer price index (CPI), } \\
2010=100\end{array}$ & 2,848 & 89.69 & 25.44 & 7.12 & 173.88 \\
\hline $\begin{array}{l}\text { Money market rate } \\
\text { (short-term interest rate), \% }\end{array}$ & 2,848 & 6.01 & 5.31 & -0.51 & 52.32 \\
\hline Interest rate on loans to the economy, $\%$ & 2,848 & 8.77 & 10.11 & 0.50 & 97.70 \\
\hline Total loans to the economy / GDP & 2,848 & 77.33 & 38.76 & 8.40 & 199.50 \\
\hline
\end{tabular}

Table 3. Descriptive statistics for the IV Probit model

\begin{tabular}{|c|c|c|c|c|c|}
\hline & $\begin{array}{l}\text { Number } \\
\text { of observations }\end{array}$ & $\begin{array}{l}\text { Mean } \\
\text { value }\end{array}$ & $\begin{array}{l}\text { Standard } \\
\text { deviation }\end{array}$ & Min. & Max. \\
\hline Credit cycle (CC) & 1954 & 0.26 & 0.44 & 0 & 1 \\
\hline Business cycle (BC) & 1954 & 0.13 & 0.34 & 0 & 1 \\
\hline Real loans, growth rate, \% year-on-year & 1954 & 4.49 & 7.77 & -53.90 & 40.82 \\
\hline Real GDP, growth rate, \% year-on-year & 1954 & 2.50 & 2.74 & -10.87 & 24.95 \\
\hline GFC & 1954 & 0.47 & 0.96 & -2.41 & 2.68 \\
\hline Gross capital inflow / GDP, \% & 1954 & 2.65 & 8.34 & -25.36 & 89.09 \\
\hline
\end{tabular}

Notes:

1) $\mathrm{BC}$ is the binary variable equal to 1 for the contraction phase of the business cycle (recession) and to 0 for the expansion phase; by analogy, $\mathrm{CC}$ is the binary variable equal to 1 for the contraction phase of the credit cycle (credit crisis) and to 0 otherwise. The indicators are determined using the BBQ algorithm (Harding and Pagan, 2002).

2) The analysed sample consists of 27 countries over the period of 1990Q1-2019Q1. The number of observations in this table and the following tables with the estimation results differs due to the different lag order of the explanatory variables used in the respective models.

3) The indicator of the global financial cycle (GFC) is the first principal component of about 800 prices for financial assets around the world; it is standardised in its construction (Miranda-Agrippino and Rey, 2020). Positive GFC values correspond to the expansion phase of the global financial cycle, while negative values correspond to the contraction phase.

4) Gross capital inflow means the total volume of external liabilities registered in item 'Other investments' (liabilities) in the countries' standard component structure of the balance of payments. 
The sample of countries that we use demonstrates also significant variation in key macroeconomic indicators - that is, annual dynamics of GDP and inflation. In particular, the sample includes countries that experienced both a significant decline in aggregate output (about-10\% YoY in terms of real GDP: Thailand in 1998, Turkey in the early and late 2000s, Greece in 2011) and significant economic growth (more than $+20 \%$ in Ireland in 2015). The same can be said of the inflation indicator. Of course, advanced economies are characterised by less volatility of key economic and banking sector indicators. In general, the analysis shows that the sample of countries is balanced in terms of periods of intensive development and periods of economic crises.

Other statistics also confirm that our sample is well-balanced. First, the sample includes countries with both near-zero or negative values of the short-term interest rate, which have been characteristic of a number of advanced economies over the past decade (due to extremely loose monetary policy and interest rates reaching a zero lower bound), and with values of the short-term interest rate exceeding $10 \%$ per annum over a long period in emerging economies (e.g. Russia, Indonesia, South Africa). Second, the sample covers periods of intensive capital inflows for countries (maximum gross inflow of up to $+89 \%$ of GDP) and periods of 'sudden stops' (see, for example, Mendoza, 2010) and significant capital outflows (maximum gross outflow of $-25 \%$ of GDP). Such differences in the dynamics of capital flows can be explained not only by significant changes in domestic fundamental factors but are also largely determined by the phase of the global financial cycle (GFC, see Miranda-Agrippino and Rey, 2020). ${ }^{15}$

\subsection{Key macro-financial indicators in the context of the global financial cycle}

Let's take a closer look at the dynamics of bank lending, GDP and interest rates in various groups of countries in the context of the global financial cycle (GFC). This is necessary as one of the three key variables in our IV Probit model of the credit cycle, along with credit supply shock and monetary policy shock, is the external financial shock, which is approximated by estimating the dependence of the dynamics of gross capital inflows on the global financial cycle

If we look at different sub-samples of countries within our overall sample, we find a noticeable positive correlation between the GFC indicator, on the one hand, and annual GDP dynamics, on the other hand, especially in the vicinity of

\footnotetext{
${ }^{15}$ In 1990-2018, we can distinguish expansion (positive values of the main component of GFC) and contraction (negative values of the main component) phases of the global financial cycle, which, as a rule, have a negative correlation with the VIX implied volatility index. For example, low VIX values (below 20 p.p.) correspond to low volatility associated with a positive assessment of the prospects for financial markets, which corresponds to the expansion phase of the global financial cycle. In contrast, high VIX values (especially over 40 p.p.) reflect investor panic and indicate the emergence of a global financial crisis, which corresponds to the contraction phase of the global financial cycle.
} 
Figure 1. Annual GDP dynamics of advanced economies in the context of GFC

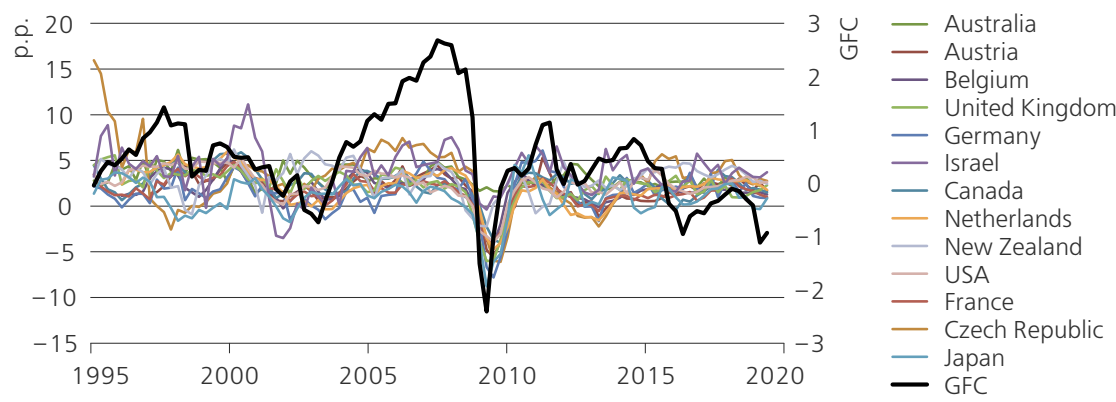

Figure 2. Annual bank lending dynamics of advanced economies in the context of GFC

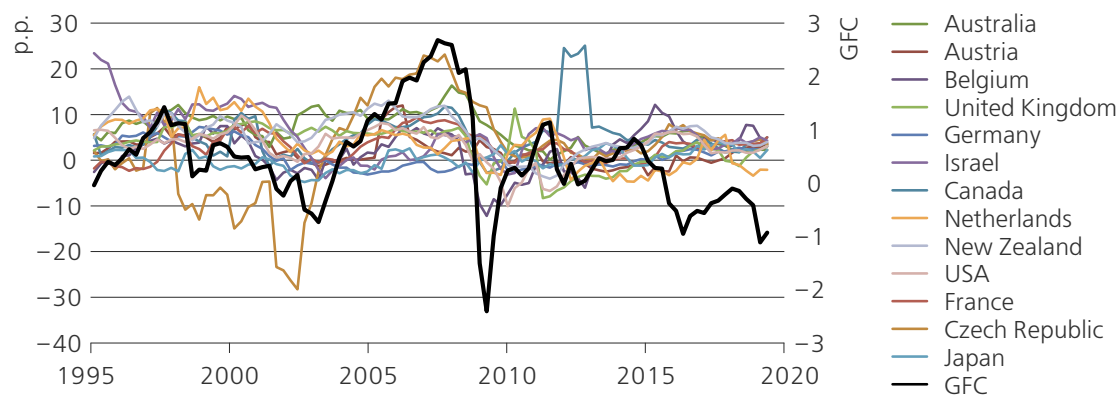

Figure 3. Annual GDP dynamics of emerging economies in the context of GFC

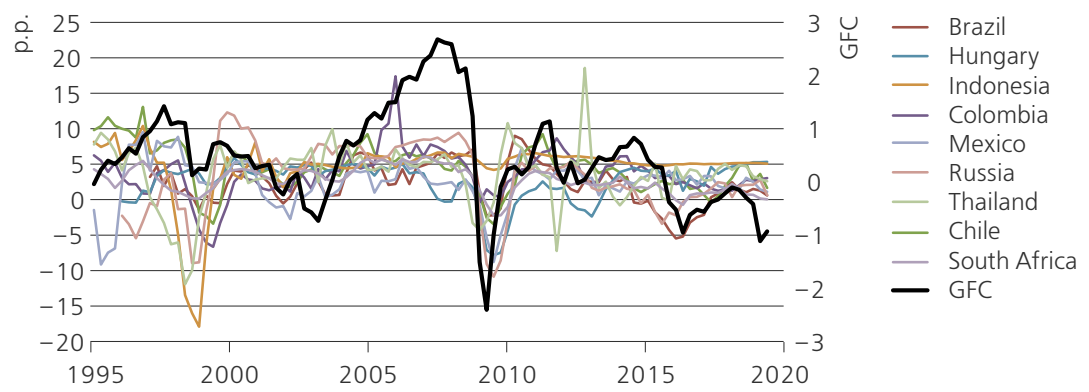

Figure 4. Annual bank lending dynamics of emerging economies in the context of GFC

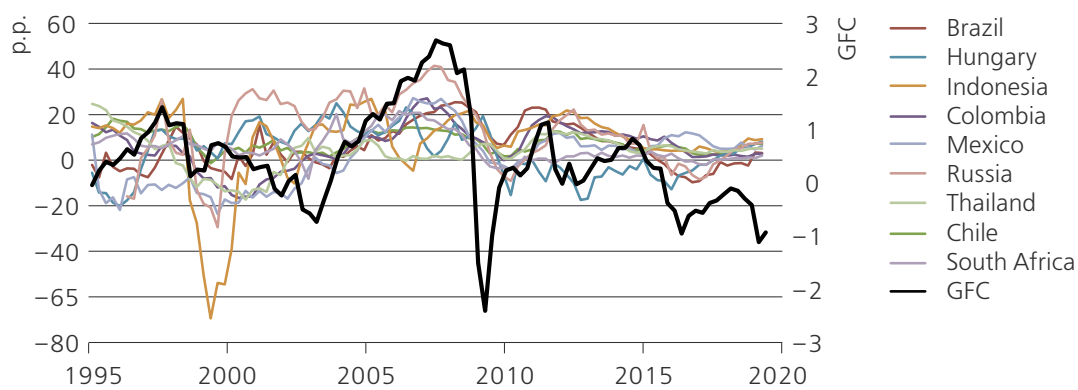


Figure 5. Annual GDP dynamics of GIPSI countries in the context of GFC

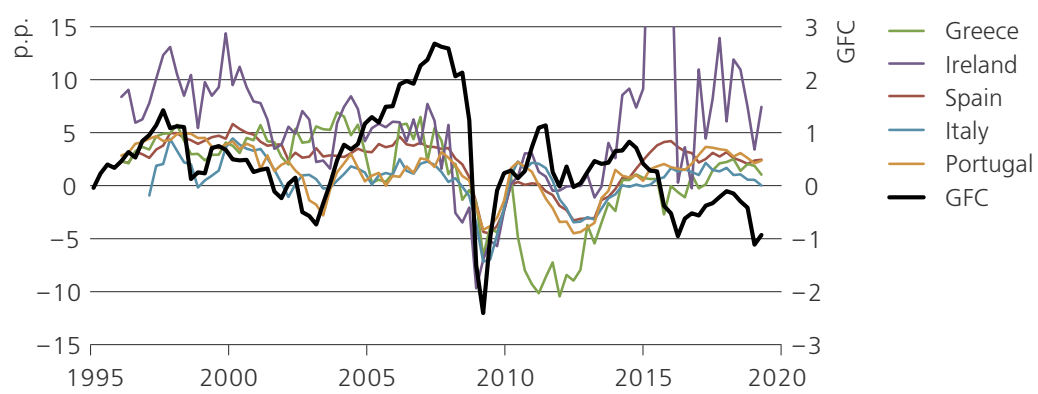

Figure 6. Annual bank lending dynamics of GIPSI countries in the context of GFC

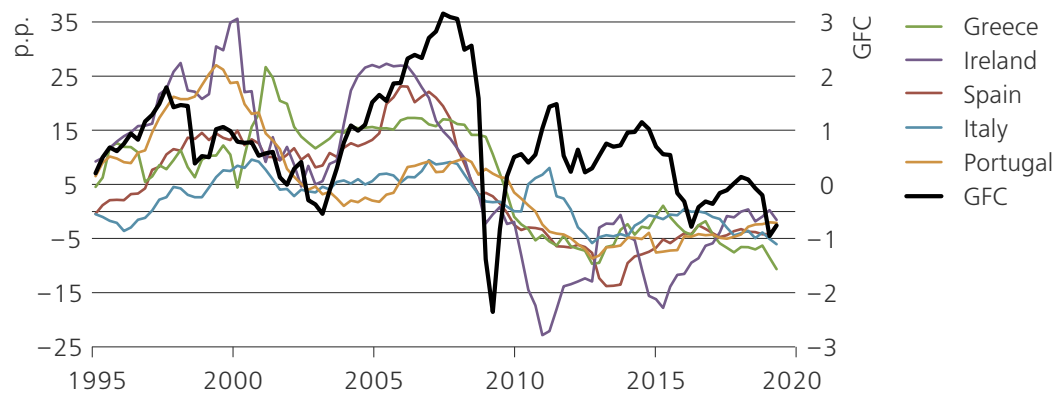

Figure 7. Short-term money market rates of emerging economies in the context of the US rate

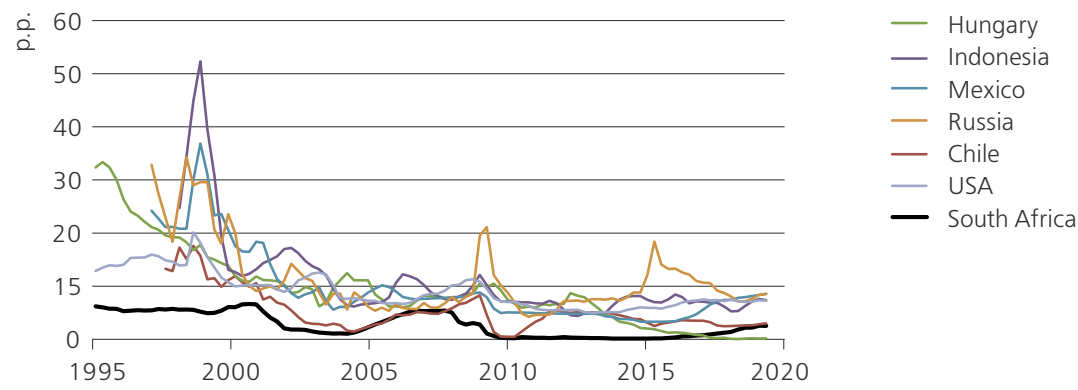

Figure 8. Short-term money market rates of advanced economies in the context of the US rate
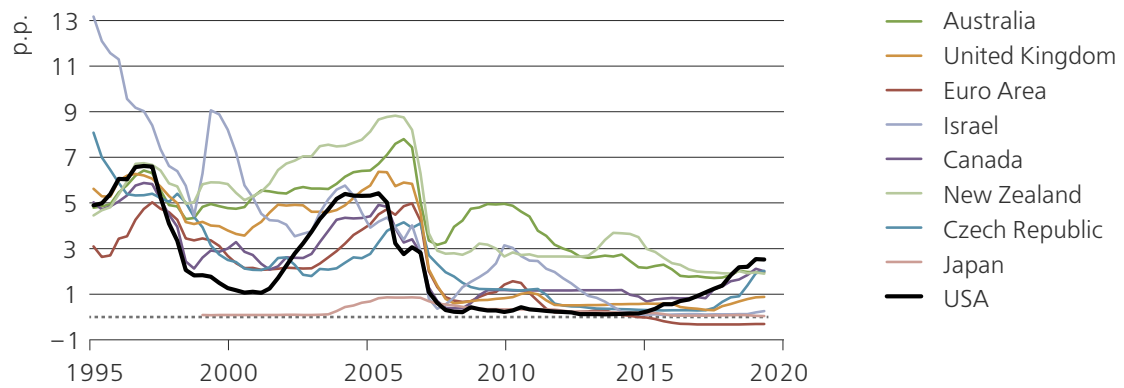
the 2007-2009 global financial crisis. This is true for the sub-samples of advanced economies (Figure 1), emerging economies (Figure 3) and such groups of countries as GIPSI (Greece, Ireland, Portugal, Spain, and Italy), which we consider for illustrative purposes (Figure 5). We see a similar positive correlation between the GFC and bank lending dynamics in the same groups of countries (Figure 2, 4 and 6 for advanced economies, emerging economies, and GIPSI, respectively). The considered relationships between the GFC indicators and the dynamics of output and bank lending in different countries are consistent with the findings of Mendoza and Terrones (2008), di Giovanni et al. (2017), and Claessens and Ghosh (2013), which show that external financial shocks have a significant impact on the internal business and credit cycles of economies.

In turn, the global financial cycle can be explained by such factors as unexpected changes in the monetary policy of global financial regulators (primarily, the US Fed; see Miranda-Agrippino and Rey, 2020). Monetary policy rates and money market rates in most countries of the world follow the dynamics of the US rate (Passari and Rey, 2015; Rey, 2016; Anaya et al., 2017; Ligonniere, 2018), and this connection is most noticeable in the last decade, after the global financial crisis of 2007-2009 (Figures 7 and 8).

Thus, by considering the GFC indicator in our IV Probit models of the credit cycle on cross-country data, we may indirectly take into account the influence of the US monetary policy on the phase of the credit cycle in certain countries.

\section{Results of regression estimates}

\subsection{SVAR approach: identifying financial and real shocks}

Based on the data used, we were able to evaluate VAR models with restrictions on the signs of impulse response functions for 33 countries, including both advanced and emerging economies. ${ }^{16}$ For each country, we plotted impulse response functions of the endogenous model variables for the identified CS, MP, $\mathrm{AD}$ and AS shocks as well as the dynamics of such shocks over time. Since a detailed description of the results for each country would take too much space, ${ }^{17}$ we will describe here the results in aggregate form, and the Appendix will detail the results for Russia as one of the countries in the sample (see Figure A1 in Appendix, showing the impulse response functions of the Russian economy for a positive credit supply shock and restrictive monetary policy shock as well as the estimated time series of both shocks).

\footnotetext{
${ }^{16}$ Australia, Austria, Belgium, Brazil, the United Kingdom, Hungary, Germany, Greece, Denmark, Israel, Indonesia, Ireland, Spain, Italy, Canada, Colombia, Korea, Malaysia, the Netherlands, New Zealand, Poland, Portugal, Russia, the USA, Thailand, Finland, France, the Czech Republic, Chile, Switzerland, Sweden, South Africa, and Japan.

${ }^{17}$ Graphs of the shock dynamics over time and the impulse response functions of the economy for each country are available by request.
} 
Figure 9. Estimated distributions of financial and real shocks, average values for countries within the selected distribution percentiles

a) Credit supply shock (CS)

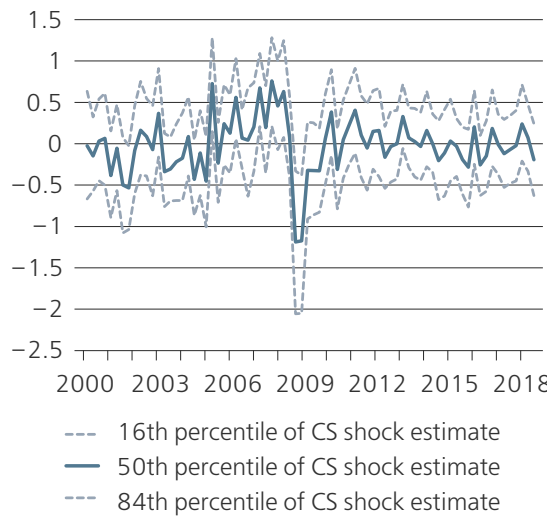

c) Aggregate demand shock (AD)

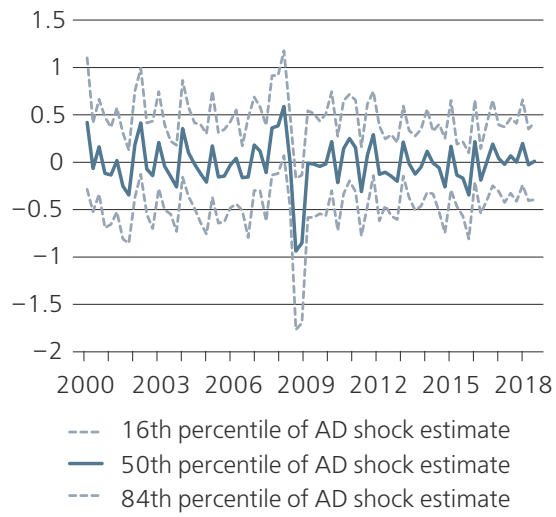

b) Monetary policy shock (MP)

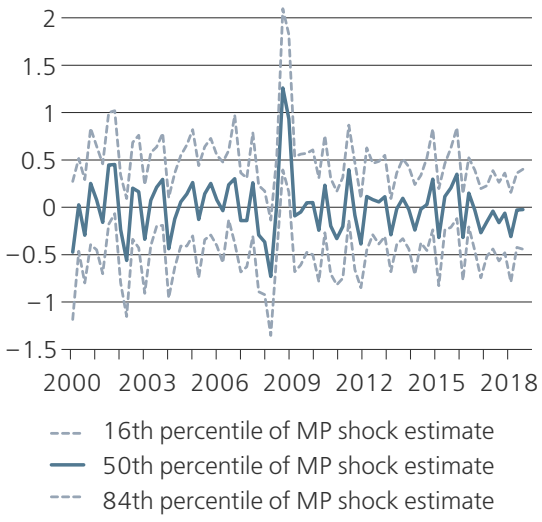

d) Aggregate supply shock (AS)

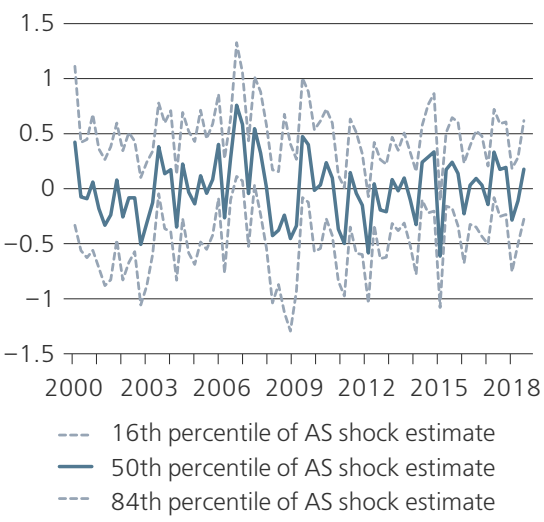

To get an idea of how the shock estimates behave by country, we analyse the dynamics of their values averaged over 33 countries for each quarter of observations (Figure 9). For example, Figure 9a shows the trajectories of cross-country mean values of credit supply (CS) shock in three percentiles of the distribution of these shock estimates: in the 16th percentile (for our purposes: low shock values), 50th percentile (median shock) and 84th percentile (for our purposes: high shock values). Positive shock values correspond to positive credit supply shocks in the economy, while negative values correspond to negative shocks. Even with such averaging, the estimates clearly indicate that in the pre-crisis period of 2004-2007 the sample countries experienced a significant positive credit supply shock, which then, in the crisis years of 2008-2009, was replaced by a sharp negative shock. 
Further, in Figure 9b, a similarly defined monetary policy (MP) shock indicates that in the same pre-crisis period there may have been a massive easing of monetary policy (negative shock values), and in the subsequent crisis period, monetary policy tightening (positive shock values).

Finally, the dynamics of the real shocks, demand shock (AD) and supply shock (AS) are also consistent with the intuition and data (Figures $9 \mathrm{c}$ and $9 \mathrm{~d}$, respectively). Note that in the pre-crisis period estimates indicate positive demand shocks, which correspond to the acceleration of economic growth and intensification of inflationary processes, and in the crisis period the AD shock values become sharply negative, which indicates the suppression of prices and economic activity in the world. The dynamics of AS shock do not have such pronounced pro-cyclical fluctuations; on the contrary, it is acyclical. This is unsurprising since supply shocks reflect technological innovation rather than accumulation of economic imbalances.

\subsection{Instrumental approach: comparative analysis of financial shocks' impact on the phases of the credit cycle}

After obtaining estimates of the time series of financial and real shocks based on the cross-country SVAR analysis (Section 4.1) and isolating the part of the intracountry variation in total capital inflows explained by the influence of the global financial cycle (GFC), ${ }^{18}$ we proceed to comparative analysis of the role of these shocks and GFC in the formation of phases the credit cycle, in particular, the probability of a credit crisis. These estimates were obtained using the IV Probit model of the credit cycle formalised by regression equations (4) and (5). We emphasise that equation (4) models the business cycle (BC) phase, and the credit cycle (CC) phase is modelled by equation (5), depending on the model value of the business cycle phase from the previous equation. Since this paper is focused on the study of credit cycles, we do not claim to provide an exhaustive description of the business cycle, giving the latter only an auxiliary role.

The estimation results for various specifications of the IV Probit model are presented in Table 4. In the first two specifications (one-step), both cycles are modelled separately; this is necessary in order to have individual benchmarks for the effects of financial and real shocks not limited by any assumptions regarding the relationship between the two cycles. In these two specifications of the standard Probit model, each of the two cycles is modelled depending on its own lagged value and on the lagged value of the other cycle, with control for a set of shocks. Next, an instrumental (two-step) specification is shown. It contains the same set of shocks,

\footnotetext{
18 To isolate the GFC-influenced variations in total capital inflows, we estimated regression equation (6) on data for 27 countries (1,954 observations in 'country/quarter' format) using country fixed effects. The result of the estimation, the coefficient $\varphi=2.598$, is significant at the $1 \%$ level. This estimate assumes that in response to one intra-sample standard deviation of GFC (0.96) the average response of aggregate capital inflows can reach $0.96 \cdot 2.598 \approx 2.5$ p.p. of GDP, which is equivalent to $30 \%$ of one intra-sample standard deviation of the ratio of aggregate capital inflows to GDP.
} 
Table 4. One- and two-step (instrumental) Probit models of credit cycles

\begin{tabular}{|c|c|c|c|c|c|c|}
\hline \multirow{3}{*}{$\begin{array}{l}\text { Equation } \\
\text { Dependent variable }\end{array}$} & \multirow{2}{*}{\multicolumn{2}{|c|}{ One-step }} & \multicolumn{2}{|l|}{ Two-step } & \multicolumn{2}{|c|}{ Two-step + shock lags } \\
\hline & & & \multirow{2}{*}{$\begin{array}{l}\text { 1st step } \\
\text { Business } \\
\text { cycle (BC) }\end{array}$} & \multirow{2}{*}{$\begin{array}{l}\text { 2nd step } \\
\text { Credit } \\
\text { cycle (CC) }\end{array}$} & \multirow{2}{*}{$\begin{array}{l}\text { 1st step } \\
\text { Business } \\
\text { cycle (BC) }\end{array}$} & \multirow{2}{*}{$\begin{array}{l}\text { 2nd step } \\
\text { Credit } \\
\text { cycle (CC) }\end{array}$} \\
\hline & $\begin{array}{l}\text { Business } \\
\text { cycle }(\mathrm{BC})\end{array}$ & $\begin{array}{l}\text { Credit } \\
\text { cycle }(\mathrm{CC})\end{array}$ & & & & \\
\hline $\mathrm{BC}$ lag $=1$ quarter & $\begin{array}{l}2.875^{* * *} \\
(0.143)\end{array}$ & $\begin{array}{l}0.709^{* * *} \\
(0.148)\end{array}$ & $\begin{array}{l}0.676^{* * *} \\
(0.027)\end{array}$ & & $\begin{array}{l}0.673^{* * *} \\
(0.027)\end{array}$ & \\
\hline CC lag $=1$ quarter & $\begin{array}{l}-0.182 \\
(0.145)\end{array}$ & $\begin{array}{l}2.851^{* * *} \\
(0.109)\end{array}$ & $\begin{array}{l}-0.027^{*} \\
(0.015)\end{array}$ & $\begin{array}{l}2.829^{* * *} \\
(0.110)\end{array}$ & $\begin{array}{l}-0.024 \\
(0.016)\end{array}$ & $\begin{array}{l}2.990^{* * *} \\
(0.127)\end{array}$ \\
\hline $\begin{array}{l}\text { Business cycle }(\widehat{B C}) \text {, } \\
\text { model value }\end{array}$ & & & & $\begin{array}{l}0.870^{\star * *} \\
(0.204)\end{array}$ & & $\begin{array}{l}0.925^{\star * *} \\
(0.238)\end{array}$ \\
\hline $\begin{array}{l}A S \text { : aggregate } \\
\text { supply shock, }\end{array}$ & $\begin{array}{l}-1.062^{* * *} \\
(0.107)\end{array}$ & & $\begin{array}{l}-0.107^{\star * *} \\
(0.011)\end{array}$ & & $\begin{array}{l}-0.105^{\star * *} \\
(0.011)\end{array}$ & \\
\hline lag $=1$ quarter & & & & & $\begin{array}{l}0.013 \\
(0.009)\end{array}$ & \\
\hline $\begin{array}{l}A D \text { : aggregate demand } \\
\text { shock, lag }=0 \text { quarters }\end{array}$ & $\begin{array}{l}-3.949^{* * *} \\
(0.700)\end{array}$ & & $\begin{array}{l}-0.350^{* * *} \\
(0.070)\end{array}$ & & $\begin{array}{l}-0.250^{* * *} \\
(0.069)\end{array}$ & \\
\hline lag $=1$ quarter & & & & & $\begin{array}{l}0.208^{* * *} \\
(0.073)\end{array}$ & \\
\hline $\begin{array}{l}\text { MP: monetary policy } \\
\text { shock, }\end{array}$ & $\begin{array}{l}3.103^{* * *} \\
(0.550)\end{array}$ & $\begin{array}{l}-0.400 \\
(0.246)\end{array}$ & $\begin{array}{l}0.287^{* * *} \\
(0.056)\end{array}$ & $\begin{array}{l}-0.484^{* * *} \\
(0.241)\end{array}$ & $\begin{array}{l}0.176^{* * *} \\
(0.054)\end{array}$ & $\begin{array}{l}-0.548^{\star *} \\
(0.243)\end{array}$ \\
\hline lag = 1 quarter & & & & & $\begin{array}{l}-0.092^{*} \\
(0.051)\end{array}$ & $\begin{array}{l}0.608^{\star * *} \\
(0.204)\end{array}$ \\
\hline \multirow[t]{2}{*}{$\begin{array}{l}C S: \text { credit supply shock, } \\
\text { lag = } 1 \text { quarter }\end{array}$} & $\begin{array}{l}-0.658^{* * *} \\
(0.084)\end{array}$ & $\begin{array}{l}-0.506^{* * *} \\
(0.082)\end{array}$ & $\begin{array}{l}-0.064^{* * *} \\
(0.010)\end{array}$ & $\begin{array}{l}-0.451^{\star * *} \\
(0.083)\end{array}$ & $\begin{array}{l}-0.052^{\star * *} \\
(0.010)\end{array}$ & $\begin{array}{l}-0.495^{\star * *} \\
(0.092)\end{array}$ \\
\hline & & & & & $\begin{array}{l}-0.001 \\
(0.009)\end{array}$ & $\begin{array}{l}0.263^{* * *} \\
(0.082)\end{array}$ \\
\hline $\begin{array}{l}\text { GCI: capital inflow } \\
\text { shock, }\end{array}$ & $\begin{array}{l}-0.023 \\
(0.026)\end{array}$ & $\begin{array}{l}-0.062^{* * *} \\
(0.021)\end{array}$ & $\begin{array}{l}-0.003 \\
(0.002)\end{array}$ & $\begin{array}{l}-0.063^{* * *} \\
(0.022)\end{array}$ & $\begin{array}{l}-0.035^{\star * *} \\
(0.006)\end{array}$ & $\begin{array}{l}0.081^{\star} \\
(0.048)\end{array}$ \\
\hline lag = 1 quarter & & & & & $\begin{array}{l}0.037^{* * *} \\
(0.006)\end{array}$ & $\begin{array}{l}-0.162^{* * *} \\
(0.051)\end{array}$ \\
\hline Constant & $\begin{array}{l}-2.295^{* * *} \\
(0.443)\end{array}$ & $\begin{array}{l}-1.478^{\star * *} \\
(0.299)\end{array}$ & $\begin{array}{l}0.054^{* *} \\
(0.025)\end{array}$ & $\begin{array}{l}-1.493^{\star * *} \\
(0.299)\end{array}$ & $\begin{array}{l}0.038 \\
(0.025)\end{array}$ & $\begin{array}{l}-1.542^{* * *} \\
(0.322)\end{array}$ \\
\hline Country fixed effects & Yes & Yes & Yes & Yes & Yes & Yes \\
\hline Number of observations & 1,827 & 1,954 & & 54 & & \\
\hline Number of countries & 27 & 27 & & & & \\
\hline Log likelihood & -266.9 & -338.2 & & 2.6 & & \\
\hline Wald test statistics & $554.3^{* * *}$ & $982.0^{* * *}$ & & $5^{* * *}$ & & *** \\
\hline \multicolumn{7}{|c|}{ Estimates of economic effects in the 2nd step: } \\
\hline$\Delta \widehat{P r}_{i t}^{M P}$ and $\Delta \widehat{P r}_{i t+1}^{M P}$ & \multicolumn{2}{|c|}{-0.009} & \multicolumn{2}{|c|}{-0.125} & \multicolumn{2}{|c|}{-0.141 and 0.157} \\
\hline$\Delta \widehat{P r}_{i t}^{c S}$ and $\Delta \widehat{P r}_{i t+1}^{c S}$ & \multicolumn{2}{|c|}{-0.031} & \multicolumn{2}{|c|}{-0.306} & \multicolumn{2}{|c|}{-0.335 and 0.178} \\
\hline$\Delta \widehat{P r}_{i t}^{G C I}$ and $\Delta \widehat{P r}_{i t+1}^{G C I}$ & \multicolumn{2}{|c|}{-0.026} & \multicolumn{2}{|c|}{-0.291} & \multicolumn{2}{|c|}{0.376 and -0.747} \\
\hline
\end{tabular}

Note: ${ }^{* * *},{ }^{* *}$, or ${ }^{\star}$ means that the coefficient estimate is significant at the $1 \%, 5 \%$, or $10 \%$ level, respectively. The values in the brackets below estimates are their robust standard errors. 
but now we set the current phase of the credit cycle depending on the current phase of the business cycle. To do this, at the first step, we model the business cycle phase, similarly to the one-step specification, and then at the second step we model the credit cycle phase that now depends on the model value of the current business cycle phase obtained in the first step and its own lagged value (see equations (4) and (5) in Section 2). This two-step specification includes only current values of financial and real shocks. Since the effects of such shocks can be non-linear over time, the final specification (two-step + shock lags) presented in the table expands the previous version of the IV Probit model by adding the first quarterly lags of all shocks along with their current values. We will treat this version of the model as the basic one. In all versions, we included country fixed effects but not time fixed effects. ${ }^{19}$ Row by row, after the estimates of the coefficients, the lower part of the table shows the estimates of the economic effects at the second step (see equations (7)-(9) in Section 2).

Key conclusions based on the simulation results are as follows: in the sample of countries under consideration, the transmission of financial shocks to the credit cycle phases is indeed non-linear (a switching effect is observed depending on the time elapsed since the shocks occurred); among these shocks, the external capital inflow (GCI) shock is at least two times stronger in economic effect than the credit supply (CS) shock, which in turn is two times stronger than the monetary policy (MP) shock.

Let us now dwell in more detail on the analysis of the obtained results.

\subsubsection{One-step specifications}

One-step models can only identify one of the three shocks, credit supply shock (CS). Monetary policy (MP) shock appears to be statistically insignificant in the credit cycle equation, and, in turn, the capital inflow (GCI) shock is statistically insignificant in the business cycle equation. This is not consistent with our expectations and does not allow for a comparative analysis of the economic effects of these three shocks when determining the phase of the credit cycle. Finally, onestep models produce clearly understated estimates of economic effects, which fit poorly with the results of previous studies (in Greenwood et al., 2020, the effects are more than 10 times higher, even with all the differences in methodology).

\subsubsection{Two-step specification without non-linear effects from shocks}

We observe significant 'added value' in the transition from one-step Probit models to two-step (instrumental) specification. In the credit cycle equation, all three shocks are identified (statistically significant at the $1 \%$ or $5 \%$ level), and

${ }^{19}$ As Schularick and Taylor (2012) note when modelling the probability of a financial crisis on a cross-country data panel, the inclusion of fixed effects over time has no practical purpose since such effects reflect aggregate shocks unaccounted for in the model, and predicting crises using such models becomes impracticable due to the impossibility of predicting unaccounted for shocks. 
estimates of the economic effects of these shocks are significantly higher and, thus, consistent with the existing studies that explore these shocks separately.

In the first step - that is, the business cycle equation, our calculations indicate that the business cycle is characterised by a certain degree of inertia, and that its lagged value plays an important role, confirming the conclusions of existing studies (Kauppi and Saikkonen, 2008; Nyberg, 2010; Antunes et al., 2018). In contrast, the lagged value of the credit cycle turns out to be of little significance in our sample, partly contradicting the findings of other studies (Reinhart and Rogoff, 2009; Claessens et al., 2012; Drehmann et al., 2012).$^{20}$ In other words, if at the current point of time a country is in the phase of recession, then at the next point in time it will probably continue being in recession; however, if this country is currently in the phase of a credit crisis, we cannot predict the next phase of the business cycle (the resulting negative coefficient indicates the possibility of a switching effect, but its value is almost insignificant and close to zero compared to similar coefficient for the first lag of the business cycle).

Further in the first step, we also find negative and statistically significant effects from both of the real shocks, aggregate supply (AS) and aggregate demand (AD). Both shocks were identified in the SVAR model as positive - that is, corresponding to increasing output in the economy. As it has been already mentioned, these two shocks are included only in the first step of the model, and since they proved to be statistically significant, we can hope to be able to use them for isolating the exogenous variation in the business cycle, which in turn is important for identifying the second step.

Restrictive monetary policy shocks statistically significantly increase the probability of business cycle corrections. This can happen via an increase in the interest rate that cools the economy down (consistent with the theory and findings of a large number of empirical studies, for example, see Bernanke et al., 2005; Barakchian and Crowe, 2013; Gertler and Karadi, 2015; Wolf, 2020). On the contrary, positive credit supply (CS) shocks statistically significantly reduce the probability of business cycle corrections, since borrowing from the domestic banking system becomes more available for the economic agents which use it to finance consumption and investment. This conclusion is also consistent with the literature (for example, see Eickmeier and Ng, 2015; Mumtaz et al., 2018; Gambetti and Musso, 2017). Similar logic is applicable to the positive external capital inflow shocks, although the estimated effect turned out to be statistically insignificant.

In the second step - that is, the credit cycle equation, we find that the fitted value of the business cycle phase obtained in the first step has a positive and statistically significant effect on the phase of the credit cycle, even taking into account the control

\footnotetext{
${ }^{20}$ The key finding of these studies is that recessions are deeper if they are accompanied by financial crises. The difference between these studies and our paper lies in the study of continuous values reflecting the magnitude of crises (intensive margin), while we analyse binary variables (extensive margin).
} 
over the lagged value of the credit cycle variable. This suggests that even if at the previous point in time the domestic banking system was in a phase of expansion of lending to the economy, in the current period the expansion phase may be replaced by a correction phase, provided that the business cycle enters a correction phase (for example, due to a negative shock of economic agents' income). ${ }^{21}$

Further, unlike the result obtained in the first step, here we find that the restrictive monetary policy shock does not cool down the credit market at the current point in time: the coefficient before the MP shock variable is not positive, but negative, and statistically significant (at the 1\% level). As we discussed before (see Section 2), this may indicate that a surprise rate hike by central banks may serve as a 'filter' keeping ex-ante less profitable/riskier business projects out of the economy. Most likely, lending growth rates turn out to be lower than in lower interest rate conditions, but these rates are now ensured by better quality of borrowers remaining in the economy after the monetary 'filter' was applied. This means that at this point in time a credit crisis is less probable. ${ }^{22}$ We will discuss possible non-linearities associated with the transmission of monetary policy shocks to the economy below, when describing the results of the final specification. Positive credit supply (CS) shocks and foreign capital inflow shocks have a stimulating instantaneous effect on the credit market that is, they reduce the probability of a credit crisis occurring in that same period (the coefficients for the corresponding variables are negative and statistically significant at the $1 \%$ level). Similar effects were also inherent in the first step, in the business cycle model. Although the CS and GCI shock variables are similar in sign to the MP shock variable, the interpretation is different. Unlike the monetary 'filter', the expansion of the credit supply and the increased external capital inflow make borrowed funds more accessible at this point in time, including for ex-ante poorer-quality borrowers using these funds not to invest in new projects but to refinance earlier loans. ${ }^{23}$ We will discuss non-linearities associated with such effects below.

\subsubsection{Two-step specification with non-linear effects of shocks}

In the simplest case, we can try to capture the non-linear effects of shocks by slightly modifying the equations of the first and second steps of the IV Probit

\footnotetext{
${ }^{21} \mathrm{Keep}$ in mind that in the first step we discovered that the background of the credit cycle has no strong correlation with the current phase of the business cycle. In this sense, the results are consistent.

22 An alternative explanation of the results can be found in the studies on the risk-taking channel of monetary policy (for example, see Maddaloni and Peydró, 2011; Jiménez et al., 2014; Dell'Ariccia et al., 2017). In particular, in the context of low interest rates, we observe a decrease in the profitability of banking operations, making banks look for riskier investment areas for their funds, in particular, lending to riskier borrowers. In terms of our results, this means that an unexpected easing of monetary policy (negative values of the MP shock variable) increases the probability of a credit crisis.

${ }^{23}$ In other words, positive credit supply shocks expand the credit market; in particular, borrowers have additional opportunities to refinance previous liabilities to credit institutions, which is usually observed during the upward phase of the credit cycle characterised by a low probability of a credit crisis (Gambetti and Musso, 2017). The same logic applies to assessing the nature of the impact of positive capital shocks (foreign capital inflow to the country), only in this case we are talking about external financial liabilities.
} 
model: we can add the first, second, and so on lags of these shocks to the explanatory variables until we get coefficient estimates for these lags which are opposite in sign to the coefficient for the zero lag. As shown by our calculations, it was sufficient to introduce the first quarterly lag for each shock along with the corresponding zero lag.

First, the coefficient in front of the zero lag of the monetary policy (MP) shock variable is still negative and statistically significant (at the $1 \%$ level), but the coefficient in front of the first lag becomes positive and also highly statistically significant. In other words, by initially serving as an ex-ante 'filter' for poorer-quality borrowers, over a longer horizon, monetary policy shock may have a negative effect on the better-quality borrowers remaining in the system since higher interest rates will make it harder for them to service their debts.

Second, the coefficient in front of the zero lag of the credit supply (CS) shock variable also remains negative and statistically significant same as before, but the coefficient in front of the first lag becomes positive and significant. The latter points to the reverse side of a positive credit supply shock: over longer horizons, economic agents become less able to pay off additional debts that appeared due to positive bank lending shock. The probability of a credit crisis grows. ${ }^{24}$

Third, the coefficient before the zero lag of the capital inflow (GCI) shock variable reverses its sign from negative to positive in the final specification, and the negative effect starts to manifest itself from the first lag. However, the estimate of the coefficient before the zero lag turns out to be of low significance (at the $10 \%$ level), and we interpret it with caution; on the contrary, the coefficient before the first lag appears to be highly significant (at the $1 \%$ level), and it seems to correspond to the effect from the model without distributed lags.

From a technical point of view, the use of the instrumental variables is justified since the results of the Wald test of exogeneity ( $p$-value was less than 0.01) reject the independence of the phases of the business and credit cycle. This means that if we applied the Probit model without using the instrumental approach, we would face a problem of endogeneity, and the validity of the estimates obtained would be low.

\subsubsection{Economic effects of financial shocks}

Let us compare the estimates of the economic effects ${ }^{25}$ of the three financial shocks on the phase of the credit cycle. To do this, we will use the final specification of the IV Probit model presented in Table 4 (see the bottom panel).

The calculation results show that the capital inflow (GCI) shock has the strongest effect. An impulse of one standard deviation of the GCI increases the probability of a

\footnotetext{
${ }^{24}$ Obviously, higher quality borrowers cannot be fully insured against negative shocks (productivity, etc.) which, if realised, could negatively affect their solvency. This, in turn, could lead to an increased risk appetite of such borrowers, which could ultimately increase the probability of a credit cycle correction.

${ }^{25}$ Economic effect is understood as the marginal effect estimated from the IV Probit model and further multiplied by one intra-sample standard deviation of the corresponding shock (see equations (7)-(9) in Section 2).
} 
credit cycle correction by $38 \%$ in the same period but significantly (by $75 \%$ ) decreases that probability in the next quarter. Descriptive statistics of assessed shocks, including their standard deviations, are given in Table A3 (see Appendix).

The credit supply (CS) shock is the second strongest, with an impulse of one standard deviation reducing the probability of a credit crisis by $34 \%$ in the same quarter but also increasing that probability by $18 \%$ in the next quarter after the shock realisation. The weaker impact of the domestic credit supply shock compared to the external one can be explained by more limited financial resources of the domestic economy, as opposed to the global one.

Finally, similarly calculated effects of monetary policy (MP) shock are $-14 \%$ in the same quarter and $+16 \%$ in the next one, respectively. The weaker impact of monetary shocks on the phases of the credit cycle compared to the domestic credit supply and external capital inflow shocks is consistent since final decisions on borrowers and rates are made by banks and not regulators.

\subsection{Credit cycles in the Russian banking system: in-sample forecasts and counterfactual analysis}

Now, we will draw conclusions for the Russian banking system that follow from the conducted cross-country analysis of credit cycles. For these purposes, we use the IV Probit model with lags of real and financial shocks (see Table 4).

We will start by illustrating the in-sample characteristics - that is, assessing whether the cross-country model can capture different phases of the credit cycle in Russia. To do this, we obtain the fitted values of the probability of a credit crisis and compared them with the actual dates of the onset of crisis events. The results are shown in Figure 10a. Our calculations show that the cross-country model correctly and confidently captures all three credit crisis episodes observed in Russia in 19982019. For 1998, the fitted values of the probability of a credit crisis reach $60 \%$, and for the periods of the global financial crisis of 2008-2009 and the local economic crisis of 2014-2016 they reach $80 \%$ and higher. On the contrary, in crisis-free periods, the fitted values of the probability are close to zero, with rare exceptions.

For comparison, we presented fitted values of a similar IV Probit version of the model where the inertia of the business and credit cycles are excluded (see Figure 10b). The comparison shows that in this case the model is also able to capture episodes of credit crises in Russia, but during such episodes the fitted values are substantially lower, in the range of $20-40 \%$, and in crisis-free episodes they are substantially higher than the near-zero values typical of the basic model shown in Figure 10a. In other words, taking the cycle inertia into account substantially increases the confidence in the estimates due to the substantial reduction of type I and II errors.

In addition, Figure 10a and 10b show the average probability of a credit crisis in our sample of 27 countries. This allows us to see whether our model is able to capture the global credit crisis episode of 2008-2009. Our calculations 
demonstrate that the fitted values of the probability of a credit crisis increase from about $10 \%$ in 2008 to over $50 \%$ in 2009 . We also note the higher model values of the probability of a credit crisis in the 2010s compared to the 2000s: the growth averaged about 20 p.p., from $10 \%$ to $30 \%$. This is largely due to the figures for the GIPSI countries, part of Latin America and, to a certain extent, Russia. This finding is illustrated in the Appendix by the examples of countries that experienced additional episodes of credit crises following the 2008-2009 global economic crisis - that is, Russia, Greece and Brazil, compared to the US economy, which had no such episodes (see Figure A2).

Figure 10. Model values of the probability of credit crisis in Russia and in the world: in-sample values

a) Taking into account the inertia of the business and credit cycles

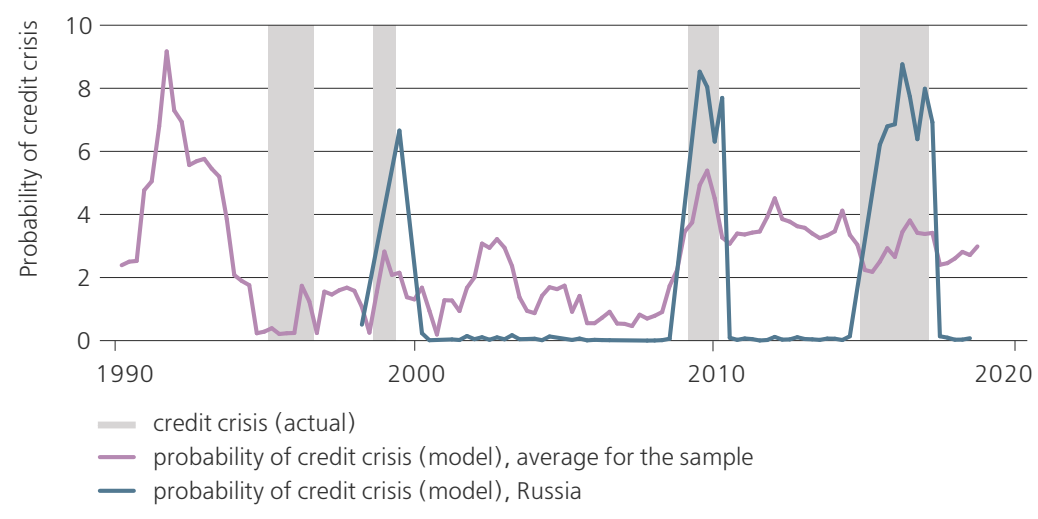

b) Excluding the inertia of the business and credit cycles

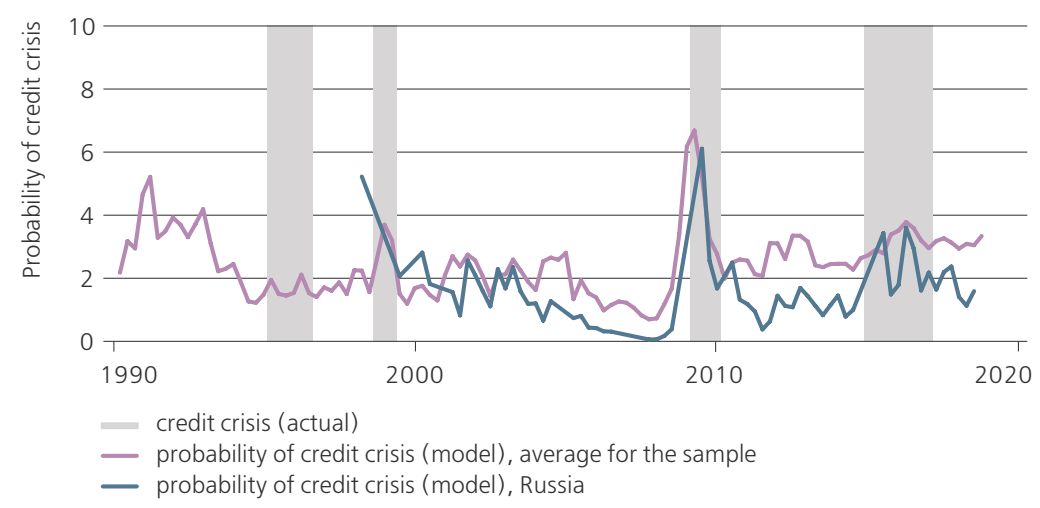

To compare the magnitude of the impact of monetary, credit and external shocks in Russia, we will conduct the following counterfactual (thought) experiment: we will calculate the values of the probability of a credit crisis in hypothetical conditions 
where only one of the three shocks is in effect, either monetary policy (counterfact 1 ) or credit supply (counterfact 2) or external capital inflow (counterfact 3), and compare these counterfactual values with the actual calculated value assuming all three shocks are in effect at the same time. For definiteness, we conduct this experiment not over the entire time interval considered earlier but only for the periods of the 2008-2009 and 2014-2015 credit crises. The calculations are based on the final specification of the IV Probit model (see Table 4): we fix the estimates of the coefficients and obtain fitted values by zeroing one or the other pair of shocks. The results are shown in Figure 11a.

Figure 11. Model values of the probability of credit crisis in Russia and in the world: a counterfactual analysis

a) Russia

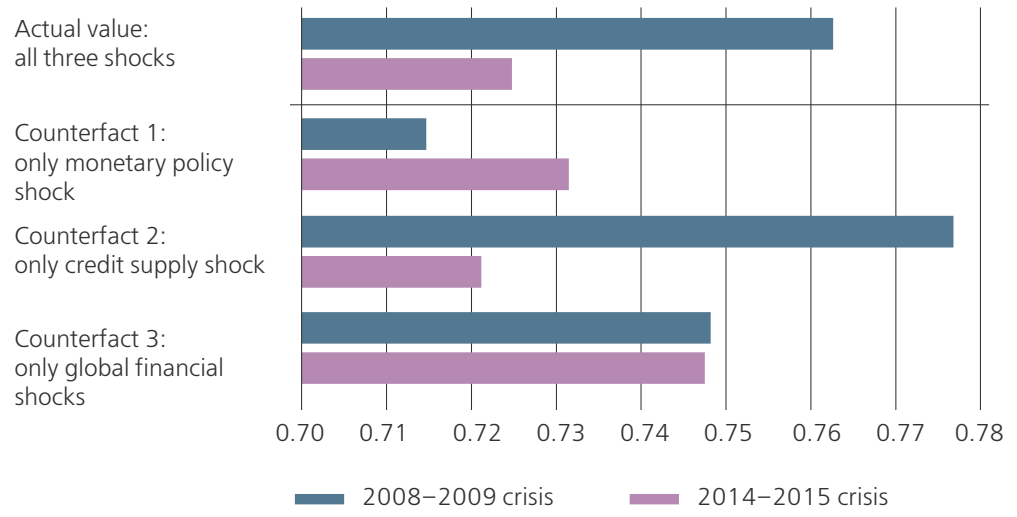

b) Sample of 27 countries, average values
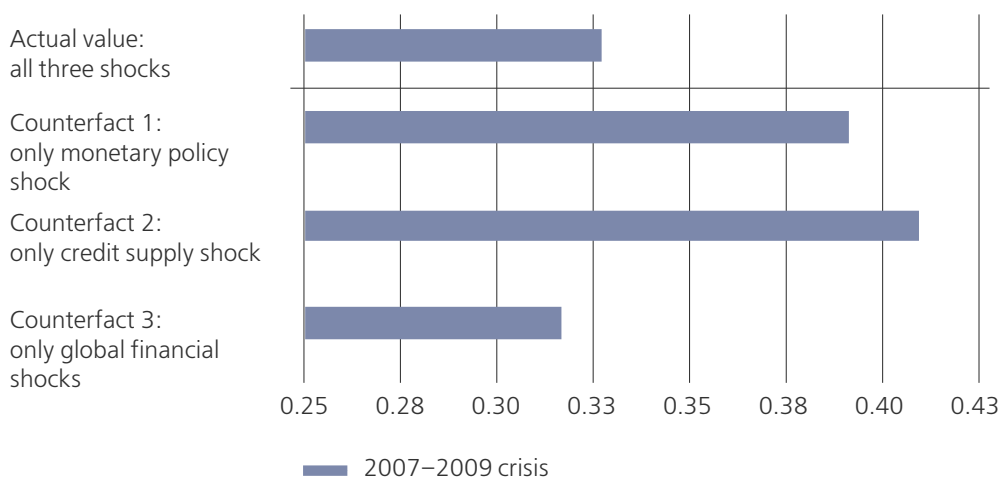

As follows from the presented calculations, the two credit crises differ in that in 2008-2009, credit supply shocks played a notably greater role than monetary policy shocks, and in 2014-2015 the situation was reversed. For example, if only 
the monetary policy shock had been in effect in the first of the two crisis periods, the probability of a credit crisis would have amounted to $71 \%$, and if only the credit supply shock had been in effect, to $78 \%$. In the second crisis period, the corresponding estimates are $73 \%$ (+2 p.p.) and $72 \%$ (-6 p.p.). This may indicate an increase in the efficiency of the Russian monetary authorities in terms of their ability to control the phases of the credit cycle and, accordingly, a relative decrease in the role of credit supply shocks. In turn, this may serve as one of the positive consequences of the Bank of Russia's transition to a policy of inflation targeting. At the same time, the role of external shocks turns out to be more significant than that of the other two types of shocks and is more stable over time: the counterfactual model values of the probability of a credit crisis are $75 \%$ for both episodes.

Finally, if we conduct the same experiment for the total sample of 27 countries during the 2007-2009 crisis (see Figure 11b), we will also get a result indicating that the contribution of credit supply shocks might have exceeded the role of monetary policy shocks; however, in contrast to the situation in Russia, the role of external shocks might be smaller rather than larger compared to monetary and credit shocks.

\subsection{Robustness analysis of key results: continuous dependent variable, control variables, and the Hodrick-Prescott filter}

To check the robustness of the results obtained for the basic version of the IV Probit model of credit cycles, we use a number of additional exercises to determine the extent to which our conclusions based on estimates of the economic effects for the three financial shocks will hold, first, when adding additional control variables in the model; second, when switching from the binary cycle to its continuous version; and, third, when switching from the BBQ algorithm for determining the binary variable of the cycle to an alternative algorithm based on the HodrickPrescott filter (HP filter).

Exercise 1: Adding new control factors to the basic IV Probit specification. In the basic specification, we focus on the effect of three financial shocks estimated from country SVAR models and control the model for the cycle inertia and country fixed effects only. Since credit crises can occur in both advanced and emerging banking sectors, country fixed effects may not fully capture the differences between these two groups of countries; therefore, in an extended specification, we additionally control for the level of financial intermediation in a country using the loan-to-GDP ratio variable (same as, for example, Schularick and Taylor, 2012). Further, neither the financial shock variables nor the cycle inertia variables reflect consumer sentiment, which in this exercise we can control for using the consumer confidence index variable (annual changes of the base index, the OECD data). Previous studies on business cycles show that such a factor plays an important role in predicting recessions (Christiansen et al., 2014; Aastveit et al., 2019). Finally, our baseline variables do not capture the global component of growth. To account for 
this factor, we control the new specification for the variable of the leading indicator of growth for the key global economy, the United States. The estimation outcomes of the new version of the IV Probit model are presented in Table A4 of the Appendix in comparison with the basic specification. The calculations show that all the findings of the basic model described above are preserved in this extended specification of the model: in particular, the discovered non-linear effects of shocks by quarter and the values of estimates of economic effects from three shocks. Any differences are only quantitative; the most notable of them is the reduction in the value of the economic effect of the external shock over a one-quarter horizon from $75 \%$ in the basic model to $58 \%$, which is still greater than the scale of the economic effects of monetary policy and credit supply shocks.

Exercise 2: Switching to continuous variables reflecting cycles. Instead of binary variables, we used variables of annual growth rates of GDP and bank loans in real terms. This also prompted us to switch from using an IV Probit model to using a CUE GMM model (Continuously Updating Estimator, Generalised Method of Moments) with a similar two steps (the first is the business cycle model, the second is the credit cycle model). These two models were compared only qualitatively - namely, we checked whether the signs and significance of the coefficients before MP, CS and GCI shocks change when switching to continuous variables. As shown by the estimation results (see Tables A5 of the Appendix), our main findings regarding the nature of the non-linearity of monetary and credit shocks remain unchanged, while conclusions on the role of external shocks differ. In particular, the coefficient in front of the zero lag of the external shock becomes insignificant, although remaining positive, and the coefficient in front of the first lag switches its sign from negative to positive (which may reflect the effect of excess lending). In this respect, the IV Probit model is preferable to this alternative, from our point of view.

Exercise 3: Alternative method of isolating cycles. Instead of the BBQ algorithm from Harding and Pagan (2002), we applied an HP filter to the annual GDP dynamics to isolate the business cycle and to the annual credit dynamics in real terms to isolate the credit cycle, separately for each of the 27 countries in the sample. The datasmoothing parameter was set assuming that the length of the credit cycle is roughly the same as the length of the business cycle $(\lambda=26,000$, for example, see Drehmann et al., 2011). If the current value of the annual GDP (loans) growth rate exceeded the value of the HP filter, we interpreted this as a growth phase and assigned a value of 0 to the new binary variable of the business cycle (credit cycle), and, conversely, assigned a value of 1 if the current value was below the HP filter. The results of the re-estimation of the IV Probit model are given in Table A6 (see Appendix). Calculations show that in the new model, the zero lags of all three shocks remain significant (at the $1 \%$ level in the case of monetary policy and credit supply shocks, at the $11 \%$ level in the case of GCI shock), but the first lags of these shocks lose their significance, and we can no longer draw a conclusion on the non-linear nature of the transmission of financial 
shocks to the economy through the credit market. For this reason, from our point of view, using the $\mathrm{BBQ}$ algorithm is preferable to the HP filter.

\section{Conclusion}

The findings of our paper show that, first, in the considered sample of 27 countries during the period of 1990-2019 the impact of financial shocks on the credit cycle could be non-linear: the data showed switching effects depending on the time elapsed since the shocks occurred. Second, among these shocks, the external capital inflow (GCI) shock was on average approximately two times stronger in its economic effect than the credit supply (CS) shock for the current and subsequent quarters. In turn, the CS shock was on average twice as strong as the monetary policy (MP) shock.

However, across countries there is a notable heterogeneity in the studied effects. We conducted a counterfactual analysis for the Russian economy and showed that during the crisis of 2014-2015 the economic effect of monetary policy shocks may have outweighed credit supply shocks. In our opinion, this may indicate an increase in the efficiency of the Russian monetary authorities in terms of their ability to control the phases of the credit cycle and, accordingly, a relative decrease in the role of credit supply shocks.

Appendix is available at

http://rjmf.econs.online/en; dx.doi.org/10.31477/rjmf.202004.45

\section{References}

Aastveit, K. A., Anundsen, A. K. and Herstad, E. I. (2019). Residential Investment and Recession Predictability. International Journal of Forecasting, 35(4), pp. 1790-1799. doi: 10.1016/j.ijforecast.2018.09.008

Aikman, D., Haldane, A. G. and Nelson, B. D. (2015). Curbing the Credit Cycle. The Economic Journal, 125(585), pp. 1072-1109. doi: 10.1111/ecoj.12113

Anaya, P., Hachula, M. and Offermanns, C. J. (2017). Spillovers of U.S. Unconventional Monetary Policy to Emerging Markets: The Role of Capital Flows. Journal of International Money and Finance, 73(B), pp. 275-295. doi: 10.1016/j.jimonfin.2017.02.008

Antunes, A., Bonfim, D., Monteiro, N. and Rodrigues, P. M. M. (2018) Forecasting Banking Crises with Dynamic Panel Probit Models. International Journal of Forecasting, 34(2), pp. 249-275. doi: 10.1016/j.ijforecast.2017.12.003

Barakchian, S. M. and Crowe, C. (2013). Monetary Policy Matters: Evidence from New Shocks Data. Journal of Monetary Economics, 60(8), pp. 950-966.

doi: 10.1016/j.jmoneco.2013.09.006 
Bernanke, B. S., Boivin, J. and Eliasz, P. (2005). Measuring the Effects of Monetary Policy: A Factor-Augmented Vector Autoregressive (FAVAR) Approach. Quarterly Journal of Economics, 120(1), pp. 387-422. doi: 10.1162/0033553053327452

Brunnermeier, M. K. and Sannikov, Y. A. (2014). Macroeconomic Model with a Financial Sector. American Economic Review, 104(2), pp. 379-421. doi: 10.1257/aer.104.2.379

Christiansen, C., Eriksen, J. N. and Moller, S. V. (2014). Forecasting US Recessions: The Role of Sentiment. Journal of Banking and Finance, 49, pp. 459-468. doi: 10.1016/j.jbankfin.2014.06.017

Claessens, S. and Ghosh, S. R. (2013). Capital Flow Volatility and Systemic Risk in Emerging Markets: The Policy Toolkit. In: O. Canuto and S. R. Ghosh, eds. Dealing with the Challenges of Macro Financial Linkages in Emerging Markets. doi: 10.1596/978-1-4648-0002-3

Claessens, S., Kose, M. A. and Terrones, M. E. (2012). How Do Business and Financial Cycles Interact? Journal of International Economics, 87(1), pp. 178-190. doi: 10.1016/j.jinteco.2011.11.008

Dell'Ariccia, G., Laeven, L. and Suarez, G. A. (2017). Bank Leverage and Monetary Policy's Risk-Taking Channel: Evidence from the United States. Journal of Finance, 72(2), pp. 613-654. doi: 10.1111/jofi.12467

Demeshev, B. and Malakhovskaya, O. (2016). Macroeconomic Forecasting with a Litterman's BVAR Model. HSE Economic Journal, 20(4), pp. 691-710. [In Russian].

Deryugina, E. and Ponomarenko, A. (2015). Accounting for Post-Crisis Macroeconomic Developments in Russia: A Large Bayesian Vector Autoregression Model Approach. Emerging Markets Finance and Trade, 51(6), pp. 1261-1275. doi: 10.1080/1540496X.2015.1069125

Detken, C., Weeken, O., Alessi, L., Bonfim, D., Boucinha, M. M., Castro, C., Frontczak, S., Giordana, G., Giese, J., Jahn, N., Kakes, J., Klaus, B., Lang, J. H., Puzanova, N. and Welz, P. (2014). Operationalising the Countercyclical Capital Buffer: Indicator Selection, Threshold Identification and Calibration Options. ESRB Occasional Paper Series, N5.

Di Giovanni, J., Kalemli-Ozcan, S., Ulu, M. F. and Baskaya, Y. S. (2017). International Spillovers and Local Credit Cycles. NBER Working Paper, N 23149. doi: 10.3386/w23149

Drehmann, M., Borio, C. and Tsatsaronis, K. (2011). Anchoring Countercyclical Capital Buffers: The Role of Credit Aggregates. International Journal of Central Banking, 7(4), pp. 189-240.

Drehmann, M., Borio, C. and Tsatsaronis, K. (2012). Characterising the Financial Cycle: Don't Lose Sight of the Medium Term! BIS Working Paper, N 380.

Duprey, T., Klaus, B. and Peltonen, T. (2017). Dating Systemic Financial Stress Episodes in the EU Countries. Journal of Financial Stability, 32, pp. 30-56. doi: 10.1016/j.jfs.2017.07.004. 
Eickmeier, S. and Ng, T. (2015). How Do US Credit Supply Shocks Propagate Internationally? A GVAR Approach. European Economic Review, 74, pp. 128-145. doi: 10.1016/j.euroecorev.2014.11.011

Gambetti, L. and Musso, A. (2017). Loan Supply Shocks and the Business Cycle. Journal of Applied Econometrics, 32(4), pp. 764-782. doi: 10.1002/jae.2537

Gertler, M. and Karadi, P. (2015). Monetary Policy Surprises, Credit Costs, and Economic Activity. American Economic Journal: Macroeconomics, 7(1), pp. 44-76. doi: $10.1257 /$ mac.20130329

Gertler, M. and Kiyotaki, N. (2010). Financial Intermediation and Credit Policy in Business Cycle Analysis. In: B. M. Friedman and M. Woodford, eds. Handbook of Monetary Economics, Vol. 3. Elsevier, pp. 547-599. doi: 10.1016/B978-0-444-53238-1.00011-9

Gertler, M., Kiyotaki, N. and Prestipino, A. A. (2020). Macroeconomic Model with Financial Panics. Review of Economic Studies. 87(1), pp. 240-288. doi: $10.1093 /$ restud/rdz032

Greenwood, R., Hanson, S. G., Shleifer, A. and Sørensen, J. A. (2020). Predictable Financial Crises. NBER Working Paper, N 27396. doi: 10.3386/w27396

Harding, D. and Pagan, A. (2002). Dissecting the Cycle: A Methodological Investigation. Journal of Monetary Economic, 49(2), pp. 365-381. doi: 10.1016/S0304-3932(01)00108-8

He, Z. and Krishnamurthy, A. A. (2012). Model of Capital and Crises. The Review of Economic Studies, 79(2), pp. 735-777. doi: 10.1093/restud/rdr036

Jermann, U. and Quadrini, V. (2012). Macroeconomic Effects of Financial Shocks. American Economic Review, 102(1), pp. 238-271. doi: 10.1257/aer.102.1.238

Jiménez, G., Ongena, S., Peydró, J. L. and Saurina, J. (2014). Hazardous Times for Monetary Policy: What do Twenty-Three Million Bank Loans Say About the Effects of Monetary Policy on Credit Risk-Taking? Econometrica, 82(2), pp. 463-505. doi: 10.3982/ECTA10104

Kauppi, H. and Saikkonen, P. (2008). Predicting U.S. Recessions with Dynamic Binary Response Models. The Review of Economics and Statistics, 90(4), pp. 777-791. doi: $10.1162 /$ rest.90.4.777

Kilian, L. and Lütkepohl, H. (2017). Structural Vector Autoregressive Analysis. Cambridge University Press.

Laeven, L. and Valencia, F. (2020). Systemic Banking Crises Database II. IMF Economic Review, 68, pp. 307-361. doi: 10.1057/s41308-020-00107-3

Ligonniere, S. (2018). Trilemma, Dilemma and Global Players. Journal of International Money and Finance, 85(6), pp. 20-39. doi: 10.1016/j.jimonfin.2018.03.001

Maddaloni, A. and Peydró, J. L. (2011). Bank Risk-Taking, Securitization, Supervision, and Low Interest Rates: Evidence from the Euro-Area and the U.S. Lending Standards. Review of Financial Studies, 24(6), pp. 2121-2165. doi: 10.1093/rfs/hhr015

Mendoza, E. G. (2010). Sudden Stops, Financial Crises, and Leverage. American Economic Review, 100(5), pp. 1941-1966. doi: 10.1257/aer.100.5.1941 
Mendoza, E. G. and Terrones, M. E. (2008). An Anatomy of Credit Booms: Evidence from Macro Aggregates and Micro Data. NBER Working Paper, N 14049. doi: $10.3386 /$ w1 14049

Miranda-Agrippino, S. and Rey, H. (2020). U.S. Monetary Policy and the Global Financial Cycle. Review of Economic Studies, 87(6), pp. 2754-2776. doi: 10.1093/ restud/rdaa019

Mumtaz, H., Pinter, G. and Theodoridis, K. (2018). What do VARs Tell Us about the Impact of a Credit Supply Shock? International Economic Review, 59(2), pp. 625-646. doi: 10.1111/iere.12282

Nyberg, H. (2010). Dynamic Probit Models and Financial Variables in Recession Forecasting. Journal of Forecasting, 29(1-2), pp. 215-230. doi: 10.1002/for.1161

Passari, E. and Rey, H. (2015). Financial Flows and the International Monetary System. Economic Journal, 125(584), pp. 675-698. doi: 10.1111/ecoj.12268

Perri, F. and Quadrini, V. (2018). International Recessions. American Economic Review, 108(4-5), pp. 935-984. doi: 10.1257/aer.20140412

Pestova, A. and Mamonov, M. (2016a). A Survey of Methods for Macroeconomic Forecasting: Looking for Perspective Directions in Russia. Voprosy Ekonomiki, 6, pp. 45-75. [In Russian]. doi:10.32609/0042-8736-2016-6-45-75

Pestova, A. and Mamonov, M. (2016b). Estimating the Influence of Different Shocks on Macroeconomic Indicators and Developing Conditional Forecasts on the Basis of BVAR Model for the Russian Economy. Economic Policy, 11(4), pp. 56-92. [In Russian]. doi: 10.18288/1994-5124-2016-4-03

Reinhart, C. and Rogoff, K. S. (2009). The Aftermath of Financial Crises. American Economic Review, 99(2), pp. 466-472. doi: 10.1257/aer.99.2.466

Rey, H. (2016). International Channels of Transmission of Monetary Policy and the Mundellian Trilemma. IMF Economic Review, 64(1), pp. 6-35. doi: 10.1057/imfer.2016.4

Schularick, M. and Taylor, A. (2012). Credit Booms Gone Bust: Monetary Policy, Leverage Cycles, and Financial Crises, 1870-2008. American Economic Review, 102(2), pp. 1029-1061. doi: 10.1257/aer.102.2.1029

Sims, C. (1980). Comparison of Interwar and Postwar Business Cycles: Monetarism Reconsidered. NBER Working Paper, N 14049. doi: 10.3386/w0430

Uhlig, H. (2005). What are the Effects of Monetary Policy on Output? Results from an Agnostic Identification Procedure. Journal of Monetary Economics, 52(2), pp. 381-419. doi: 10.1016/j.jmoneco.2004.05.007

Wolf, C. K. (2020). SVAR (Mis)identification and the Real Effects of Monetary Policy Shocks. American Economic Journal: Macroeconomics, 12(4), pp. 1-32. doi: $10.1257 / \mathrm{mac} .20180328$ 